\title{
PEDAGOGIA EMPREENDEDORA NA UNIVERSIDADE: DIVERSAS PERCEPÇÕES
}

\author{
Deborah Breda da Silva ${ }^{1}$ \\ Fernanda Henz ${ }^{2}$ \\ Silvana Neumann Martins ${ }^{3}$
}

\begin{abstract}
Resumo: A nova configuração de mundo, globalizado e tecnológico, exige sujeitos empreendedores, proativos, dinâmicos, estrategistas, cooperativos, que saibam arriscar, ousar e inovar a fim de atender às constantes mudanças e a exigência de profissionais capazes de utilizar sua criatividade para gerar inovação. Nesse sentido, o papel que a universidade desempenha é complexo, e deve visar o acompanhamento do dinamismo da contemporaneidade. Assumir esse papel de formação de indivíduos com perfis diferenciados necessita da quebra da postura de ensino tradicional, e a busca por novas formas de ensinar e de aprender. A educação transformadora propicia ambientes de ensino e de aprendizagem favoráveis à formação desses novos sujeitos, que sejam empreendedores e protagonistas em relaçáo a sua aprendizagem, de forma que saibam lidar com as demandas impostas pelo mercado de trabalho, pelo seu contexto social e pela sua própria vida. A Pedagogia Empreendedora, associada às Metodologias Ativas, surgem com um primeiro passo potencializador para a mudança do sistema de ensino. Com o objetivo de atender a esse novo fazer pedagógico e a melhoria do ensino, este estudo traz para reflexáo a percepçáo de acadêmicos em relação ao desenvolvimento da pedagogia empreendedora nas aulas de graduação. De modo geral, percebeu-se que os métodos ativos de ensino propostos por esta metodologia favoreceram o ambiente de aprendizagem, à medida que permitiu que os estudantes se tornassem mais ativos, criativos e empreendedores. Os resultados apontaram que, na percepção dos sujeitos participantes desta pesquisa, a pedagogia empreendedora e as metodologias ativas promoveram evolução no aprendizado e crescimento pessoal.
\end{abstract}

Palavras-chave: Pedagogia Empreendedora. Acadêmicos. Universidade. Metodologias Ativas.

1 Acadêmica do Curso de Nutrição (Univates), Bolsista de Iniciação Científica FAPERGS.

2 Graduada em Pedagogia (Univates).

3 Doutora em Ensino, Docente da Univates. 


\title{
ENTREPRENEURIAL PEDAGOGY IN THE UNIVERSITY: DIVERSE PERCEPTIONS
}

\begin{abstract}
The new world configuration, globalized and technological, requires entrepreneurs, proactive, dynamic, strategists, cooperative, who know how to risk, dare and innovate in order to meet the constant changes and the requirement of professionals capable of using their creativity to generate innovation. In this sense, the role that the university plays is complex, and should aim at monitoring the dynamism of contemporaneity. Assuming this role of training individuals with differentiated profiles needs the breaking of the traditional teaching posture, and the search for new ways of teaching and learning. Transformed education provides teaching and learning environments conducive to the construction of these new subjects, who are entrepreneurs and protagonists, so that they can deal with the demands imposed by the labor market, its social context and its own life. The Entrepreneurial Pedagogy associated with Active Methodologies emerges with a first step that is potentiating the change of the education system. In the objective of attending to this new pedagogical practice and the improvement of teaching, this study brings to the reflection the perception of academics in relation to the development of entrepreneurial pedagogy in undergraduate classes. In general, it was found that the active teaching methods proposed by this methodology favored the learning environment as it allowed the students to become more active, creative and enterprising. Finally, the results pointed out that, in the perception of the subjects participating in this research, the entrepreneurial pedagogy and the active methodologies promoted evolution in learning and personal growth.
\end{abstract}

Keywords: Entrepreneurial Pedagogy. Academics. University. Active Methodologies.

\section{Introduçáo}

Vivemos em um mundo globalizado, tecnológico, caracterizado por constantes mudanças e a exigência de profissionais que atendam às novas demandas do mercado de trabalho. Essa nova configuração exige sujeitos empreendedores, proativos, dinâmicos, estrategistas, cooperativos, que saibam arriscar, ousar e inovar. Sujeitos capazes de utilizar sua criatividade para gerar inovação e mobilizar ações engajadas com o desenvolvimento em prol do contexto no qual estão inseridos.

Já se foi o tempo em que o conhecimento era limitado, o emprego estável e o diploma universitário garantia de empregabilidade. Assim, o papel que a universidade desempenha é complexo, vai além do repasse de informações, da transmissão de conhecimentos e da formação de mão de obra. De acordo com Volpi (1996, p. 17-18), cabe à universidade:

[...] produzir o saber buscando o equilíbrio entre conteúdo social e a excelência acadêmica especificamente profissional, num explícito comprometimento com a elevação das condições de vida a níveis mais dignos e fraternos, numa significativa interação com o entorno social onde se situa, cumprindo, assim, o papel que cada vez mais é chamada a desempenhar.

Nesse sentido, ir ao encontro das novas teorias que se apresentam, propiciando um ambiente de ensino e de aprendizagem favorável à formação desse indivíduo com perfil diferenciado constitui-se como desafio rumo a uma educação 
transformadora, preocupada com a formação de sujeitos empreendedores. O saber empreendedor, segundo Dolabela (2003, p. 29), "ultrapassa o domínio de conteúdos científicos, técnicos, instrumentais" e por isso constitui-se como uma ação essencialmente humana, através da qual habilidades empreendedoras são desenvolvidas ao longo da vida.

Rompendo com a concepção tradicional de educação, esse enfoque requer práticas pedagógicas mediadas por metodologias ativas de ensino, entendidas como meio de potencializar o protagonismo e o perfil empreendedor dos acadêmicos. Autores como Anastasiou \& Alves (2009), Berbel (2011) e Moran (2007, 2015) reforçam os contributos de práticas pedagógicas inovadoras mediante o uso do método ativo, em que o aluno é considerado o centro dos processos de ensino e de aprendizagem. Neste cenário, o papel do professor consiste em atuar como mediador, orientador ou facilitador dos processos de ensinar e de aprender, corroborando para que o aluno desenvolva e aprimore o próprio espírito empreendedor.

Pautado na perspectiva de um novo fazer pedagógico e na melhoria da qualidade do ensino, o Centro de Gestão Organizacional (CGO), da Universidade do Vale do Taquari - Univates, localizada no Vale do Taquari/RS/Brasil, desenvolveu, entre os anos de 2014 e 2015, a partir de um projeto que promoveu o desenvolvimento de uma rede de cooperação entre os professores do CGO, estudos, fóruns e planejamento de práticas pedagógicas inovadoras e empreendedoras envolvendo o método ativo. As situações de aprendizagem articuladas foram desenvolvidas em 21 turmas do Centro de Gestão Organizacional (CGO), nos anos de 2015 e 2016.

Dado esse entendimento, este artigo traz para reflexão as percepções dos acadêmicos da disciplina de Empreendedorismo, sobre sua aprendizagem mediante o método ativo. Ressalta-se que essa disciplina, ofertada ao longo do semestre 2016/A, foi uma das 17 turmas em que essas práticas, norteadas por metodologias ativas, foram desenvolvidas. Para tal, foi aplicado questionário, composto por perguntas abertas e fechadas, aos 45 acadêmicos da disciplina, no final do semestre letivo. Os dados coletados no questionário foram analisados a partir da análise textual discursiva Moraes (2007).

Em conformidade com a ementa, a disciplina aborda conceitos sobre empreendedorismo, características dos empreendedores e a importância dos empreendedores para o desenvolvimento da sociedade, estendendo a reflexão para a necessária aproximação entre universidade/empresa e a formação de sujeitos com perfil empreendedor e não com perfil de empregados.

\section{Metodologias ativas de ensino e a pedagogia empreendedora}

É recorrente no Ensino Superior a necessidade de estudos e práticas pedagógicas que busquem novos meios de se relacionar com o conhecimento, ultrapassando concepções de uma aprendizagem passiva e um ensino puramente técnico centrado no repasse de informações. Nos estudos de Anastasiou \& Alves (2009) reafirmamos tais pressupostos, evidenciando nos argumentos das 
autoras a necessidade de uma mudança ao que tange a organização das aulas no ambiente universitário, rompendo com a conotação do 'assistir aula' ou a exposição do conteúdo pelo professor em direção a uma ação que perpassa o 'fazer aulas', mobilizando a construção permanente do conhecimento dos sujeitos envolvidos sobre determinado saber. Nas palavras de Masetto (2003, p.73) esse entendimento requer "uma relação que desenvolva entre professores e alunos a co-responsabilidade pelo aprendizado", bem como reflete a necessidade de uma prática dialógica, de respeito mútuo e reciprocidade como defendida por Freire (ano). Ao invés de observarmos um professor sentado em sua mesa ensinando alunos posicionados enfileirados em suas carteiras, nos deparamos com uma figura docente disposta a pesquisar e construir o conhecimento junto aos acadêmicos (MASETTO, 2003).

Nessa perspectiva, pensando na articulação de novas práxis e na possibilidade de um aprender do aluno, observamos que os cursos de graduação, com destaque a área da saúde, pioneira em trabalhar na perspectiva do método ativo, têm sido mobilizados a utilizarem as metodologias ativas de ensino em sala de aula.

De acordo com Berbel (2011), o método ativo baseia-se em formas de desenvolver o processo de aprender no qual, por meio de experiências concretas ou simuladas, busca-se soluções para problemáticas encontradas em diferentes contextos. Essa aproximação entre teoria e prática contribui para uma aprendizagem mais eficaz, significativa e consciente (FREIRE, 1996).

O professor é a figura do facilitador, do orientador ou mediador, entre tantas outras características, para que o estudante possa tecer com autonomia novas redes de significação com o conhecimento. Nas palavras de Anastasiou \& Alves (2009) o professor deverá ser um verdadeiro estrategista, capaz de pesquisar, estudar e propor as melhores ferramentas facilitadoras para apropriação do conhecimento. Nesse meio, professor e alunos são vistos e entendidos enquanto sujeitos ativos dos processos de ensino e de aprendizagem, cujas ações são complementadas na prática diária.

Como Moran (2015) aponta, é necessário as metodologias estejam em consonância com os objetivos previstos, isto é, para os alunos se tornarem ativos é necessário que eles sejam expostos a situações que estimulem seu potencial de tomada de decisão e proatividade.

$\mathrm{Na}$ área da educação, diversas são as estratégias de ensino baseadas em metodologias ativas, que favorecem que o aluno se torne o próprio gestor de sua aprendizagem, dentre elas: estudo de caso, estudo de texto, seminários, aula expositiva dialogada, fórum, Philips 66, grupo de verbalização e de observação $(\mathrm{GO} / \mathrm{GV})$, júri simulado, portfólio, mapa conceitual, método de projetos, pesquisa científica, aprendizagem baseada em problemas (PBL), metodologia da problematização, aula invertida, entre outros (ANASTASIOU \& ALVES, 2009; BERBEL, 2011; MARION \& MARION, 2006; MORAN, 2015).

No ambiente universitário, a aula expositiva é uma das estratégias mais utilizadas, e possibilita que o aluno também exponha seus conhecimentos, 
complementado os saberes do professor, em uma troca enriquecedora. Essas trocas, entre docente e discente, considera a participação ativa de ambas as partes, valorizando os conhecimentos prévios, vivências e individualidades, provocando a criação de novos olhares para o objeto de estudo (ANASTASIOU \& ALVES, 2009).

Em suma, compreendemos que as metodologias ativas, articuladas ao uso de diferentes estratégias de ensino, trazem novos elementos ao contexto da aula universitária inovadora, motivando a curiosidade, o protagonismo e o perfil empreendedor dos sujeitos envolvidos em seus processos de ensino e de aprendizagem. O desafio, por sua vez, consiste em instigar o estudante a construir o próprio conhecimento de forma crítica-reflexiva percebendo a importância deste para o contexto no qual está inserido e no exercício da profissão. A seguir, expandiremos a reflexão sobre o ensino de empreendedorismo na Universidade.

Empreendedores são sujeitos com características inovadoras, proativas e com facilidade em identificar novas oportunidades (ZAMPIER; TAKAHASHI, 2011). Considerando isto, cabe refletir sobre maneiras de desenvolver essas habilidades. Os autores Bitencourt (2005) e Freitas e Brandão (2006) colocam em destaque o processo de aprendizagem como precursor do desenvolvimento do perfil empreendedor nos indivíduos, uma vez que a aprendizagem é um processo de evolução e aquisição de competências, e sem aprendizagem não existe evolução.

De acordo com Jacques Filion, “o empreendedorismo se aprende”, uma vez que se considera possível conceber aulas e cursos que adotem estratégias de aprendizado adaptadas à lógica do campo de estudo, com uma abordagem onde o aluno é levado a definir e estruturar contextos e a entender as etapas de sua evolução (FILION, 1999, p. 15).

O empreendedorismo ainda é um assunto novo que progressivamente tem sido discutido também nas instituições de ensino. Nesse contexto, a valorização do conhecimento como potencializador de ideias inovadoras, característica de ações realizadas por empreendedores, se situa principalmente nas experiências do ensino superior. Percebe-se que uma educação com foco na formação de empreendedores é fundamental diante dos desafios gerados pela sociedade e pelo mercado de trabalho. Porém, ensinar é empreender é diferente de transformar a sala de aula em espaço que foque em formar sujeitos "empregáveis". Assim, a formação de empreendedores concentra-se em estimular o aluno a buscar a inovação e deixar a mente fluir, deixar as ideias correrem soltas até se transformarem em oportunidades (BASTOS; RIBEIRO, 2011, p.8).

Para Dolabela (2008), "o empreendedor é alguém que sonha e busca transformar o seu sonho em realidade" e, a partir disso, pode gerar e distribuir riquezas. A abordagem principal da pedagogia de Dolabela não é o enriquecimento pessoal, mas o envolvimento do indivíduo, de forma ativa e inovadora, na construção do desenvolvimento social. Assim, Dolabela defende que é preciso que os alunos "desenvolvam o potencial de sonhar" (DOLABELA, 2008, p. 13).

Existem quatro pilares básicos que conduzem a educação em diversos níveis: 
1) aprender a conhecer - aprender a aprender para beneficiar-se das oportunidades oferecidas;

2) aprender a fazer - no âmbito das diversas exigências sociais;

3) aprender a viver juntos, a conviver - realizar projetos comuns e preparar-se para gerir conflitos;

4) aprender a ser - agir com autonomia, discernimento e responsabilidade pessoal (DELORS et al., 1998; BERLIM et al., 2006, p. 03).

Deste modo, os autores relacionam os pilares da educação com a pedagogia empreendedora, uma vez que esta deve oportunizar a criatividade e a iniciativa. Os espaços de ensino e de aprendizagem devem valorizar os sonhos e o planejamento para o futuro. Sabe-se que a educação de qualidade não segue apenas um caminho, portanto, cada instituição de ensino deve compreender a realidade social e o contexto na qual está inserida, e considerando sua posição, reformular seu currículo de forma que proponha conhecimentos e desenvolva habilidades e competências empreendedoras (BERLIM et al., 2006).

A Pedagogia Empreendedora é uma metodologia de ensino e de aprendizagem apoiada em um pensamento visionário e facilitador, que objetiva auxiliar os processos de aprendizagem e as ações relacionadas ao empreendedorismo. Tratase, portanto, do olhar para o ensino e desenvolvimento do empreendedorismo considerando elementos que favoreçam o autodesenvolvimento do aluno, como identidade, cooperação, inovação e criatividade (DOLABELA; FILION, 2014).

Os autores Dolabela e Filion (2014) sugerem que o meio mais poderoso de desenvolvimento do empreendedorismo é através do sistema educacional, por meio deste, a pedagogia empreendedora propõe exercícios em que os discentes aprendem a sonhar, e, a pensar em estratégias de transformar seus sonhos em realidade através de ações. Para tanto, é preciso romper a barreira que define o ensino como transferência de conhecimentos, e ressaltar a aprendizagem pautada em métodos alternativos que estimulem o pensamento imaginativo.

Sabendo que o empreendedorismo não é um dom para poucos, mas uma característica que pode ser aprendida (FILION, 2004; FILION; BOURION, 2008), a pedagogia empreendedora surgiu como uma modificadora dos padrões de ensino, criando em sala de aula um lugar propício para que o aluno seja ativo e desenvolva sua habilidade de empreender, e o professor assuma o papel de facilitador desse processo de desenvolvimento de uma nova forma de pensar (DOLABELA; FILION, 2014).

Assim, percebe-se o empreendedorismo como um propulsor de mudanças no sistema tradicional de ensino, rompendo com modelos e padrões culturais préestabelecidos e favorecendo que os estudantes se tornem agentes livres e ativos, capazes de sonhar, capazes de realizar. 


\section{Metologia}

Este artigo se trata de um estudo de caso com abordagem qualiquantitativa. Para atingir os objetivos propostos foram aplicados questionários, compostos por cinco perguntas abertas e uma pergunta fechada, com questões referentes à percepção dos acadêmicos em relação à metodologia desenvolvida na aula da disciplina de Empreendedorismo, que foi pautada em práticas pedagógicas inovadoras e empreendedoras envolvendo o método ativo e em relação ao desenvolvimento e à evolução da aprendizagem ao longo do semestre.

A aplicação dos questionários ocorreu no final do semestre A do ano de 2016, a escolha desta turma se deu, pois o professor desta turma, participou de todas as atividades de capacitação realizadas pelo CGO durante os anos de 2015 e 2016.

A amostra a ser analisada corresponde às respostas dos 45 acadêmicos da disciplina. Estes dados coletados a partir do questionário foram analisados à luz dos pressupostos da análise textual discursiva, proposta por Moraes (2007). Em relação aos dados quantitativos, procedeu-se a análise estatística (BARBETTA, 2008). Para garantir o anonimato dos acadêmicos, eles foram denominados de A1, A2, A3 e, assim, sucessivamente.

\section{Análise dos dados}

Constatou-se, por meio análise dos dados quantitativos, que 100\% ( $\mathrm{n}=45)$ dos sujeitos participantes afirmaram ter gosto por frequentar a disciplina de Empreendedorismo, devido à metodologia diferenciada utilizada pelo professor ao conduzir as aulas ao longo do semestre. Dos entrevistados, 99\% ( $\mathrm{n}=44)$ perceberam diferença significativa na metodologia da disciplina em comparação a outras disciplinas dos cursos de graduação oferecidos pela Univates. Essas diferenças dizem respeito às potencialidades do método ativo, de forma que os sujeitos perceberam que seus processos de ensino e de aprendizagem foram mais efetivos e proveitosos.

Cabe salientar que a disciplina de Empreendedorismo é uma disciplina que consta na matriz curricular de muitos dos cursos de graduação oferecidos pela instituição. Por isso, nesta disciplina, alunos de diversas áreas do conhecimento, convivem ao longo de um semestre, proporcionando uma interação muito interessante o que, provavelmente, pode contribuir para a edificação do perfil empreendedor nos alunos. Em relação à evolução do aprendizado dos discentes, fazendo um comparativo entre o "eu aluno" no início da disciplina e o desenvolvimento até o final do semestre, $95,5 \%(\mathrm{n}=43)$ declararam ter notado uma evolução significativa em seu aprendizado e na compreensão do papel do aluno em sala de aula, como protagonista de seu próprio crescimento intelectual, como pessoa e como futuro profissional. Desta forma, constata-se, através das percepções dos sujeitos envolvidos, que o método ativo aliado com o conteúdo programático da disciplina de Empreendedorismo permitiu que os graduandos 
assumissem uma postura crítica-reflexiva diante do seu papel no contexto de sala de aula e no contexto social.

Os dados discutidos até o momento podem ser visualizados no gráfico que segue:

Gráfico 1 - Percepções dos acadêmicos sobre sua aprendizagem

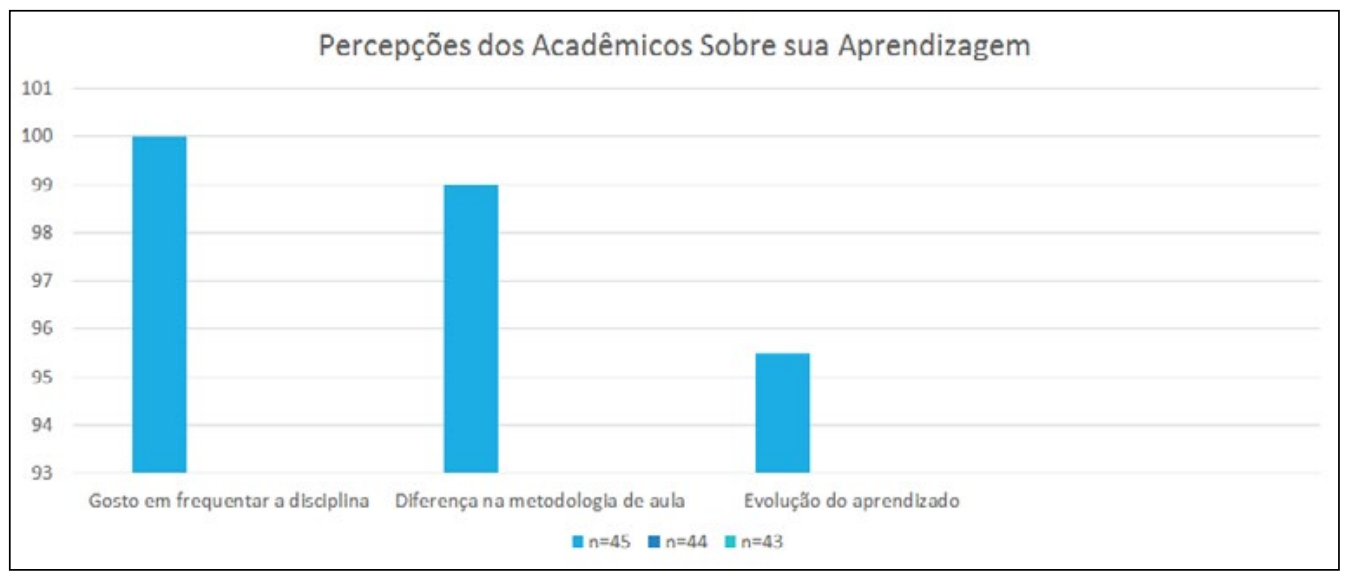

Fonte: Dos autores.

Por fim, foi proposto aos graduandos que atribuíssem um conceito numérico de 0 (zero) a 10 (dez) para o uso de metodologias ativas na didática da disciplina, sendo $0=$ totalmente inútil e $10=$ totalmente útil. Assim, a média final pontuou a disciplina com o conceito de 9,45, reforçando a efetividade dos métodos ativos em sala de aula.

A partir da Análise Textual Discursiva emergiram três principais categorias, descritas a seguir. A primeira refere-se ao contentamento dos acadêmicos em relação às aulas da disciplina de Empreendedorismo. Em seguida, ser discutido a relevância da pedagogia empreendedora na matriz curricular de cursos de Ensino Superior, e, por fim, analisou-se a evolução do aprendizado dos acadêmicos no decorrer do semestre, comparando a disciplina em questão a outras que não utilizaram métodos ativos.

\subsection{O gosto por frequentar as aulas de Empreendedorismo}

As aulas da disciplina de Empreendedorismo são caracterizadas pelo uso de métodos ativos, que instigam o acadêmico a ser o protagonista de seu próprio aprendizado, fazendo com que tanto o docente quanto o discente saiam de sua zona de conforto e produzam novas formas de ensinar e de aprender.

Em relação à aprovação dos acadêmicos a respeito das aulas de Empreendedorismo, todos os entrevistados afirmaram que gostaram de frequentar as aulas da disciplina, isto é, a totalidade dos alunos $(\mathrm{n}=45)$ avaliou positivamente 
as metodologias utilizadas em aula ao longo do semestre. Ao encontro destas afirmações, apresentamos algumas falas que evidenciam a satisfação dos acadêmicos no que diz respeito à metodologia desenvolvida em sala de aula:

\section{"Conteúdo interessante, prende a atenção" A3 \\ "As aulas são diferentes, divertidas, por isso acaba se tornando prazerosa" A6 \\ "A aula é ministrada de forma alegre, prática e motivadora" A18 \\ "É diferente da metodologia das outras disciplinas, é melhor de prestar atenção" A44}

Seguindo nesse pensamento, Berbel (2011) afirma que as metodologias ativas têm a potencialidade de despertar curiosidade nos alunos, favorecendo a motivação e estimulando os sentimentos de engajamento, percepção de competência e de pertencimento e a persistência nos estudos. Reeve (2009) aponta que, ao se perceberem como autônomos, os alunos apresentam resultados positivos em relação à: motivação (apresentando motivação intrínseca, a percepção de competência, pertencimento, curiosidade, internalização de valores); engajamento (com emoções positivas, persistências, presença nas aulas, não reprovam ou se evadem da escola); desenvolvimento (evidenciando autoestima, autovalor, preferência por desafios ótimos, criatividade); aprendizagem (melhor entendimento conceitual, processamento profundo de informações, usa de estratégias autorreguladas); melhoria do desempenho em notas, nas atividades, nos resultados em testes padronizados); e estado psicológico apresentando indicadores de bem-estar, satisfação.

Corroborando estas colocações, seguem algumas colocações dos acadêmicos:

"Aulas diferenciadas, dá aos alunos mais vontade de participar" A9

"A gente aprende se questionando e se relacionando com várias ideias" A19

"As aulas abrem nossa visão para muitas coisas, não só o lado empreendedor, mas a forma de ver o mundo" A25

"A forma com que o professor passa a aula é muito boa, diferente de todas as outras, é uma aula que dá vontade de vir" A40

"São aulas diferenciadas; forma como é ministrada nos comprova que o professor tem conhecimento e dominio dos temas, isso faz com que nós fiquemos atentos ao conteúdo" A42

As atividades desenvolvidas em aula possuem o propósito de ensinar, assim, devem ser apreciadas por todos aqueles que participam deste processo (ALVES, 2003). Os processos de aprendizagem que envolvem a autoiniciativa geram um conhecimento mais efetivo e duradouro (ROGER,1986). A produção de novos saberes, portanto, requer a convicção de que a mudança é possível, através do exercício da curiosidade, da intuição, da emoção e da responsabilização (FREIRE, 1999). 
Desta forma, percebe-se que os métodos ativos em sala de aula propõem formas de desenvolver o processo de aprender, utilizando experiências reais ou simuladas, buscando condições de solucionar com sucesso os desafios do processo de aprendizagem, em diferentes contextos. A disciplina de Empreendedorismo ao adotar o uso de metodologias ativas apresentou resultados positivos em relação a aceitabilidade e aceitabilidade dos acadêmicos.

\subsection{A pedagogia empreendedora no Ensino Superior}

A vida é urbana e o conhecimento não tem fronteira, a ideia de emprego único acabou e os fazeres pedagógicos devem permitir que os estudantes, quando procuram a universidade para serem felizes e acharem um norte para sua profissão, encontrem as respostas para seus questionamentos (PANIZZI, 2006). Os dizeres da autora nos levam a acreditar que a universidade deve ter uma postura sensível, dinâmica, responsável, independente, participativa e empreendedora. Assim, na tentativa de enfrentar essas questões, as instituições de ensino têm buscado caminhos de reestruturação e renovação de seus projetos pedagógicos, objetivando à instauração de um ambiente de ensino e de aprendizagem que seja favorável à construção desse novo homem e capaz de atender a essas novas demandas (MARTINS, 2010).

Nesse sentido, a Pedagogia Empreendedora assume o desafio de reconstruir os processos de ensinar e de aprender, e focar na mudança de pensamento e de ação tanto do professor como do aluno, levando a universidade a se responsabilizar por conscientizar, instigar e contribuir para a formação de pessoas criativas, empreendedoras e comprometidas com o desenvolvimento coletivo (MARTINS, 2010).

Pensando na mudança da educação no Ensino Superior, a adoção da pedagogia empreendedora em sala de aula é imprescindível na construção de um novo aluno, consciente, líder, inovador, ético e que se orienta por princípios e convicções, permitindo-se sonhar e alcançar seus objetivos (DOLABELA, 2007). Indo ao encontro destas percepções, os alunos entrevistados apontaram as potencialidades desta metodologia de ensino:

"Tem um potencial de ensino elevado, pois se traz a teoria para a prática" A28

"Não são aulas cansativas com PPT's intermináveis ou filmes com duração de três horas. Temos nesta aula muita interação, inclusive traz̧endo pessoas de fora para expor seus exemplos de vida" A34

'Não é uma aula expositiva maçante, cansativa, o professor faz o aluno envolver-se com os assuntos, sempre tem uma novidade, a questão do projeto social isso foi muito gratificante, os empreendedores do vale um estímulo a mais" A39

“A integração aluno X professor” A12 
"A disiciplina nos faz ver que mesmo que o caminho seja difícil, devemos persistir e isso faz que sentimos mais vivos, com mais vontade de conhecer sobre os conteúdos apresentados" A20

A partir destas colocações, pode-se perceber que a Pedagogia Empreendedora, por meio de sua metodologia ativa, permite que o estudante se aproxime mais do professor e do conteúdo apresentado, despertando interesse e motivando a busca de novos conhecimentos. Além disso, os estudantes entrevistados, apontam que essa metodologia torna a aula mais atrativa e menos maçante, potencializando os processos de ensino e de aprendizagem.

Deste modo, percebe-se que o empreendedorismo desperta novas formas de aprendizado e de relacionamento na sala de aula universitária. Pode-se destacar, também, que essa nova forma de ensinar, acompanhada de seu papel social, busca formar universitários com perfis diferenciados. E como ensinar através dessa nova forma? De acordo com Schein (1980), o novo compõe-se de quatro etapas: percepção, mudança de atitude, mudança de comportamento e fixação do novo comportamento.

Com a proposta da Pedagogia Empreendedora dá-se o passo inicial para essas mudanças significativas nos espaços de ensino. A forma de conduzir a aula, mais ativa e eficiente, interioriza essas mudanças no próprio aluno, que por consequência, se torna mais ativo e interessado pelos seus processos de aprendizagem (BERBEL, 2011). Em relação à metodologia adotada na disciplina, os estudantes afirmaram:

"Essas aulas que são mais práticas que fazo aluno interagir mais é muito mais proveitoso aprendo muito + assim!” A1

"Fácil entendimento da disciplina; aula muito envolvente; melhor relação entre alunos" A8

"Nos surge interesse natural pelo assunto, não por obrigação" A25

"Nos faz pensar de forma mais aberta" A30

Essas colocações evidenciam que as metodologias ativas em sala de aula favorecem o aprendizado, transformando positivamente a sala de aula, tornando-a um espaço de inovação, criatividade, motivação e movimento para dentro da mesma (MARTINS, 2010). De acordo com Freire (2003, p.22 e 23): "Ensinar não é transferir conhecimento, mas criar as possibilidades para a sua produção ou sua construção. Quem ensina aprende ao ensinar e quem aprende ensina ao aprender." Essas possibilidades mencionadas pelo autor e o gosto por aprender, podem, possivelmente, serem alcançadas através da Pedagogia Empreendedora.

\subsection{A evoluçáo do aprendizado dos acadêmicos}

Os questionários foram aplicados aos acadêmicos no final do semestre. Desta forma, os alunos foram questionados a respeito de suas percepções diante de sua evolução no aprendizado no decorrer da disciplina. Além disso, foi solicitado que descrevessem o porquê dessa evolução. 
Isto posto, os estudantes destacaram aspectos que contribuíram para sua evolução:

"Aprendi a perder medo, e a ter mais coragem para novos desafios, e que precisamos transformar as nossas ideias em negócios" A6

"Mudei muito minha visão empreendedora do mundo" A11

"É muito legal ter mentes brilhantes, somos abertos ao novo, de várias formas" A15

"Hoje, no final desta disciplina, estão com outra visão para o mundo, com possibilidades, inovação, persistência, bumildade...” A21

"Me tornei uma pessoa mais curiosa" A33

"Percebi que mudei bastante minha visão sobre algumas coisas" A45

Pode-se perceber que a evolução no aprendizado está diretamente ligada com as mudanças de pensamento dos estudantes. Ao mudarem sua visão, e se permitirem assumir novos papéis, dentro e fora de sala de aula, o potencial de aprendizado evoluiu. Além disso, essa nova postura crítica-reflexiva permitiu que os acadêmicos desenvolvessem outras características como visão empreendedora, curiosidade, criatividade e inovação.

Esses aspectos vão ao encontro das colocações de Masetto (2003), quando afirma que, ao utilizar metodologias ativas de ensino em sala de aula, o aluno assume uma nova postura, que instiga a iniciativa, a busca por respostas, o levantamento de hipóteses e o estabelecimento de suas próprias conclusões. Sabendo que as formas de ensinar afetam diretamente as formas de aprender, as Instituições de Ensino têm como dever educar baseando-se em valores como autonomia, independência, capacidade para inovar, para assumir riscos e atuar em ambientes instáveis, pois diante do ambiente turbulento em que vive a sociedade atual, estes valores serão capazes de direcionar o país ao desenvolvimento. Assim, o empreendedorismo na universidade é o primeiro passo na criação de uma cultura empreendedora (DOLABELA, 1999).

Para que a formação abranja todas essas características ela necessita de adequação dos conteúdos e das práticas pedagógicas, que sejam mais apropriadas para atingir seus objetivos, e não utilizem apenas métodos tradicionais de transmissão de conhecimentos (HENRIQUE, DA CUNH, 2008). A evolução do aprendizado está nas construções realizadas entre aluno-aluno e aluno-professor, de forma que o conhecimento não seja imposto, mas transmitido de forma que motive a busca por mais e mais, dando sequência ao processo de evolução (MARTINS, 2010).

Ainda em relação à utilização de metodologias ativas, os acadêmicos afirmaram ter notado diferenças entre essa metodologia utilizada na disciplina quando comparada a outras disciplinas que não a utilizam. Essas diferenças são causas potenciais da evolução no aprendizado, e, segundo eles, os aspectos positivos desse tipo de aula ocorrem por que: 
"[...] as aulas assim o aluno aprende muito mais e não fica uma coisa que o aluno decora e ao longo prazo esquece" A1

"Porque comecei a perceber o que acontece ao meu redor" A4

"Compartilhamento de novas ideias e de experiência” A32

"Pude compreender conteídos com muito mais facilidade pela forma de ensino adotada pelo professor" A43

Além das colocações supracitadas, que evidenciam que esses métodos são eficazes nos processos de aprendizagem, os acadêmicos também atribuíram uma nota à disciplina, em relação à didática, considerando o uso das metodologias ativas e da Pedagogia Empreendedora, sendo que 0 correspondeu a totalmente inútil e 10 a totalmente útil. Entre as 45 notas atribuídas, a média final foi: 9,42, demonstrando alta aceitação deste método de ensino.

A Pedagogia Empreendedora foi, portanto, uma metodologia de ensino e de aprendizagem apoiada em um pensamento inovador, facilitador e motivador auxiliando os processos de aprendizagem. Essas afirmações aproximam-se da fala de Dolabela e Filion (2014) pois, segundo os autores, a Pedagogia Empreendedora tratase do olhar para o ensino e desenvolvimento do empreendedorismo considerando elementos que favoreçam o autodesenvolvimento do aluno em seu contexto social. Através da análise das percepções dos acadêmicos e seus significados, pode-se dizer que a utilização da Pedagogia empreendedora foi eficaz para a evolução do aprendizado dos acadêmicos quanto educação, ao desenvolvimento pessoal e social e a construção de um futuro profissional.

\section{CONCLUSÁO}

A Pedagogia Empreendedora associada aos métodos ativos apresentou resultados surpreendentes no aprendizado dos acadêmicos participantes desta pesquisa. De acordo com os mesmos, esses métodos tornam a aula mais dinâmica e motivadora, e assim, os alunos a frequentam por gosto, não por obrigação. Consequentemente, o aprendizado se torna mais efetivo, pois faz sentido e se interioriza no estudante.

O papel da universidade na atualidade vem se transformando, a fim de atender a novas demandas trazidas pela dinâmica social. A adoção da Pedagogia Empreendedora nas aulas de graduação é uma das formas de evoluir a educação, e transformar o espaço de sala de aula em um ambiente propício para a formação de alunos com perfis diferenciados e com habilidades para lidar com os novos desafios iminentes na sociedade.

De modo geral, os novos métodos de ensino, que colocam em xeque o modelo tradicional e conservador, têm se mostrado como ferramentas potenciais para a melhoria dos processos de ensino e de aprendizagem, auxiliando no papel formador da Universidade. Além disso, a partir das colocações dos sujeitos participantes, o 
empreendedorismo em sala de aula ultrapassa o papel da educação, ele alcança, ainda, outros contextos e aspectos, sociais e pessoais, e prepara o acadêmico não só para os desafios de sua futura profissão, mas para os desafios da vida.

\section{Referências}

ALVES, R. Conversas sobre educação. Campinas: Verus; 2003.

ANASTASIOU, L. G. C.; ALVES, L. P. Estratégias de ensinagem. In: Anastasiou, L. G. C.; Alves, L. P. (Orgs.). Processos de ensinagem na universidade. Pressupostos para as estratégias de trabalho em aula. 5. ed. Joinville: Univille, p. 67-100, 2009

BARBETTA, Pedro Alberto. Estatística aplicada às ciências sociais. Ed. UFSC, 2008.

BASTOS, Maria Flávia; RIBEIRO, Ricardo Ferreira. Educação e empreendedorismo social: um encontro que (trans) forma cidadãos. Rev. Diálogo Educ., Curitiba, v. 11, n. 33, p.573-594, maio/ago. 2011.

BEHRENS, M. A. O paradigma da complexidade. Metodologia de projetos, contratos didáticos e portfólios. Petrópolis: Vozes, 2006.

BERBEL, Neusi Aparecida Navas. As metodologias ativas e a promoção da autonomia de estudantes. Semina: Ciências Sociais e Humanas, Londrina, v. 32, n. 1, p. 25-40, jan./jun. 2011.

BERLIM, Clara Geni et al. Princípios e práticas do empreendedorismo:

BITENCOURT, C. C. Gestão de competências e aprendizagem nas organizações. São Leopoldo/RS: Unisinos, 2005.

DELORS, Jacques et al. Educação: um tesouro a descobrir: relatório para a Unesco da Comissão Internacional sobre Educação para o século XXI. 1998.

DOLABELA, Fernando. Capital social e empreendedorismo. 2008.

DOLABELA, Fernando. O ensino de empreendedorismo: panorama brasileiro.

INSTITUTO EUVALDO LODI. Empreendedorismo: ciência, técnica e arte, v. 2, p. 83-97, 1999.

DOLABELA, Fernando. Pedagogia empreendedora. Revista de Negócios, v. 9, n. 2, 2007.

DOLABELA, Fernando; FILION, Louis Jacques. Fazendo revolução no Brasil: a introdução da pedagogia empreendedora nos estágios iniciais da educação. Revista ReGePe, v. 2, n. 3, p. 134-181, 2014.

DOLABELA, Fernando; FILION, Louis Jacques. Fazendo revolução no Brasil: a introdução da pedagogia empreendedora nos estágios iniciais da educação. REGEPERevista de Empreendedorismo e Gestão de Pequenas Empresas, v. 2, n. 3, 2014.

DOLABELA. Fernando. Pedagogia Empreendedora. São Paulo: Editora de Cultura, 2003. 
FARIAS, Isabel Maria Sabino de [et al.]. Didática e docência: aprendendo a profissão. Brasília: Liber Livro, 2009.

FILION , L. J.; BOURION. C. Les représentations entrepreneuriales. Revue internationale de psychosociologie, v. 14, n. 32, 2008.

FILION, L. J. Operators and visionaries: differences in the entrepreneurial and managerial systems of two types of entrepreneurs. International Journal of Entrepreneurship and Small Business, v.1, n.1, pp. 35-55, 2004.

FILION, Louis. J. Visão e relações: elementos para um metamodelo empreendedor. RAE - Revista de Administração de Empresas, FGV, São Paulo, vol. 33, no. 6, p. 50-61. 1993.

FILLION, Louis Jacques. Empreendedorismo: empreendedores e proprietários-gerentes de seus próprios negócios. Rev. de Administração. São Paulo, v. 34, n.2 1999.

FREIRE, P. Educação e mudança. São Paulo: Paz e Terra; 1999.

FREIRE, Paulo. Pedagogia da autonomia: saberes necessários à prática educativa. 28. ed. São Paulo: Paz e Terra, 2003.

FREIRE, Paulo. Pedagogia da autonomia: saberes necessários à prática educativa. São Paulo: Paz e Terra, 1996.

FREITAS, I. A. de.; BRANDÃO, H. P. Trilhas de aprendizagem como estratégias de TD\&E. In: BORGESANDRADE, J. E.; ABBAD, G. DA S.; MOURÃO, L. Treinamento, desenvolvimento e educação em organizações e trabalho: Fundamentos para a gestão de pessoas. Porto Alegre: Artmed, 2006. p. 97-113.

HENRIQUE, Daniel Christian; DA CUNH, Sieglinde Kindl. Práticas didáticopedagógicas no ensino de empreendedorismo em cursos de graduação e pós-graduação nacionais e internacionais. Revista de Administração Mackenzie (Mackenzie Management Review), v. 9, n. 5, 2008.

MARION, José Carlos; MARION, Arnaldo Luís Costa. Metodologias de ensino na área de negócios. Para cursos de administração, gestão, contabilidade e MBA. São Paulo: Atlas, 2006.

MARTINS, Silvana Neumann. Educação empreendedora transformando o ensino superior: diversos olhares de estudantes sobre professores empreendedores. 2010.

MASETTO, Marcos. Competência pedagógica do professor universitário. São Paulo: Summus, 2003.

MORAES, R. Uma tempestade de luz: a compreensão possibilitada pela análise textual discursiva. In: MORAES, R; GALIAZZI, M. C. (orgs.). Análise Textual Discursiva. Ijuí: Unijuí, 2007.

MORAN, José Manuel. A educação que desejamos: novos desafios e como chegar lá. Campinas, SP: Papirus, 2007. 
MORAN, José Manuel. Mudando a educação com metodologias ativas. In C. A. Souza \& O. E. T. Morales, (Orgs). Coleção Mídias Contemporâneas. Convergências Midiáticas, Educação e Cidadania: aproximações jovens. PG: Foca Foto-PROEX/UEPG, 2015, v. 2, p. 15-33. Recuperado em 30 agosto, 2016, de http://www2.eca.usp.br/moran/ wp-content/uploads/2013/12/mudando_moran.pdf

OSÓRIO, L. C. Psicologia grupal: uma nova disciplina para o advento de uma era. Porto Alegre: Aritmed, 2003.

PANIZZI, Wrana. Universidade para quê? Porto Alegre: Libretos, 2006.

REEVE, J. Why teachers adopt a controlling motivating style toward students and how they can become more autonomy supportive. Educational Psychologist, Hillsdale, v. 44, n. 3, p. 159-175, 2009.

ROGER, C. Liberdade de aprender em nossa década. $2^{a}$ ed. Porto Alegre: Artes Médicas; 1986.

SHEIN, E. Organizational psychology. New Jersey: Prentice Hall, 1980.

VEIGA, Ilma Passos Alencastro. O seminário como técnica de ensino socializado. In: VEIGA, Ilma Passos Alencastro (org). Técnicas de ensino: por que não? Campinas: Papirus, 1991. p.103-113.

VOLPI, Marina Tazón. A universidade e sua responsabilidade social. Porto Alegre: EDIPUCRS, 1996.

ZAMPIER, Marcia Aparecida; TAKAHASHI, Adriana Roseli Wünsch. Competências empreendedoras e processos de aprendizagem empreendedora: modelo conceitual de pesquisa. CADERNOS EBAPE. BR, v. 9, Edição Especial, artigo 6, Rio de Janeiro, Jul. 2011 (p.564-585). 